\title{
A Study on the Impact of the Inclusion of RMB in SDR on the International Monetary System Reform
}

\author{
$\mathrm{He} \mathrm{Li}$ \\ Oxbridge College, Kunming University of Science and Technology, \\ Yunnan City, Kunming Province, 650106, China
}

\begin{abstract}
SDR is short for Special Drawing Rights and it is an international reserve asset created by the International Monetary Fund in 1969. Based on the author's research and practical experience, this paper firstly analyzed the event that SDR is included into SDR and then discussed the reform plan of the international monetary system which involves SDR. Finally, the article put forward the reform direction of the international monetary system under the new situation. The article pointed out that as economic power continues to grow since China adopted the reform and opening up, China has played an important role in global trade. Therefore, RMB will play a greater role in the new round reform of the international monetary system.
\end{abstract}

Keywords: RMB; SDR; International monetary system; Reform

\section{Introduction}

On September 30, 2016, the International Monetary Fund (IMF) announced that the Chinese currency, Renminbi, is eligible for joining its Special Drawing Rights (SDR) currency basket which officially entered into force on October 1. President Lagarde said in a statement that this reflects RMB's position is rising in the international monetary system, which is conducive to the establishment of a stronger international monetary and financial system[1]. A favourable international monetary system is a prerequisite for the sound development of the world economy. However, the current international monetary system lacks a 
reasonable operating mechanism and an orderly operating environment. In this new situation, it is worth of thinking about how to reform the international monetary system and what the future direction of its development.

\section{The Interpretation of the inclusion of RMB into SDR}

The new SDR currency basket includes USD, EUR, RMB, JPY and GBP, with weights of $41.73 \%, 30.93 \%, 10.92 \%, 8.33 \%$ and $8.09 \%$ respectively, and the corresponding volume of money is $0.58252,0.38671,1.0174,11.900$ and 0.085946. The IMF calculates the SDR interest rate weekly and will release the new rate represented by RMB for the first time on October 7, which is a new SDR interest rate calculated by the 3-month yield of government bonds. The inclusion of RMB in SDR is a milestone in RMB internationalization and a recognition of China's achievements in economic development and the reform and opening-up in the financial sector[2]. Besides, it helps to enhance the representativeness, stability and attractiveness of SDR, and promote the reform of the international monetary system. China will take the inclusion of RMB in SDR as an opportunity to further deepen financial reform and expand financial openness, so as to contribution to promoting global economic growth, maintaining global financial stability and improving the global economy governance.

\section{The Reform Program of the International Monetary System Related to SDR}

Some scholars and policy makers believe that we can establish an ultra-sovereign international monetary system based on SDR to replace the privileged position of USD with SDR. In March 2009, China's Central Bank Governor Zhou Xiaochuan issued The Thinking on the Reform of the International Monetary System on the Central Bank's official website. He proposed to create an international reserve currency which is unconnected to the sovereign state and can maintain long-term stability, so as to avoid the inherent shortcomings of taking the sovereign credit currency as a reserve currency. He believes it is the ideal goal of the international monetary system reform. It points out that SDR has the characteristics and potential to own the super-sovereign reserve currency and puts forward a series of suggestions on how to strengthen the SDR's role in the international monetary system, including promoting the SDR distribution and widening the scope of SDR. Zhou Xiaochuan's view has aroused a warm response and active discussionin in the international community[3]. Scholars and experts from other countries and international organizations also write articles to express their views. Stiglitz and other scholars believe that the establishment of a new international reserve system is useful for all countries, including the United States. The most conservative approach to creat a new global reserve system is the regular issuance 
of SDRs by the IMF; the most radical approach is to issue SDRs based on the current state of the global economy, which makes the global reserve issuance an effective tool for global macroeconomic stabilization policies. Ocampo argues that a better way to reform the international monetary system is to transform SDR into the most important international reserve asset and a tool to fund for the IMF emergency financing during crises. He also proposed reform ways to expand the use of SDR and open alternative accounts. A study conducted by the International Monetary Fund (IMF) shows that the SDR is going through a renaissance. If SDR becomes a major reserve asset, the current dollar-based international monetary system will be changed.

Another view believes that it is necessary to strengthen SDR's role in the international monetary system and to increase the share of SDR in the international monetary system, but this view does not see SDR as a substitute for the dollar. Carney argues that lessons we learned from the gold standard system, the Bretton Woods system and the current monetary system reflect that the key to the international monetary system is the regulatory mechanism rather than the choice of which currency to use as a reserve asset. Expanding the use of SDRs encourages the transformation of existing international monetary system, but SDR can not become a global currency[4]. According to Cooper, regular issuance of SDRs will help improve global imbalances and no currency will replace the USD's international position in the next decade or two. Bergsten argues that strengthening SDR's role will reduce the reliance on dollar assets and lower the impact on the US financial system when major countries with dollar reserves dupm dollar assets suddenly. Williamson believes that under the current international monetary system, the United States is over-indebted. Once the market loses its confidence in the United States, it will seriously affect the stability of the US financial market. Therefore, strengthening the role of SDR is a good choice.

In addition to the two views, the SDR alternative account mechanism is considered as a compromise proposal that can strengthen the role of SDR in the international monetary system with preserving the dollar's existing international status. Kenen suggests that the IMF set up an alternative account that allows IMF members to replace part of their dollar assets with SDR assets in alternative accounts. IMF would invest assets in alternative accounts in dollar-denominated assets and use the earnings to pay interest to SDR asset holders. This innovation can both diversify the reserve assets of the original dollar reserve holders and prevent the former dollar reserve holders from converting large amounts of US dollar reserves into other currencies so as to improve the stability of the international monetary system and maintain the international status of the US dollar. However, there are institutional deficiencies in the alternative account: countries have not reached a clear consensus on who has to bear the risks and losses.

From the above SDR-related international monetary system programs, there is a consensus among academics and experts from countries in the world and international organizations that they agree to expand the use of SDRs and strengthen SDR's role in the international monetary system. This is conducive to 
improving the stability of the current international monetary system. However, due to the various political and economic interests of various stakeholders, it still needs further discussion and negotiation on how to promote the implementation of SDR program.

\section{The Reform Direction of the International Monetary System in the New Situation}

The core of the international monetary reform is essentially the choice of international currency. In view of the existing problems of the international monetary system, different experts and scholars put forward different viewpoints of reform, which are mainly to restore the gold standard, establish supersovereign currency, form regional currency and diversify sovereign currency. Gold can be freely casted and exchanged and it can avoid the turbulence of exchange rate and the international payments imbalance[5]. However, the gold is limited and non-renewable scarce precious metal, so many countries more willing to adopt policies to encourage the inflow of gold and limit its outflow, so that the free flow of gold becomes a problem. Therefore, the recovery of the gold standard system is inappropriate. In addition, the establishment of a single currency in East Asia still lacks realistic basis. The simple currency diversification problem is that it is difficult for any sovereign currency to overcome the Triffin paradox. China's Central Bank Governor Zhou Xiaochuan believes that the super-sovereign reserve currency not only overcomes the inherent risk of sovereign credit currency, but also provides a possibility for the regulation of global liquidity, such as special drawing rights SDR. This view has been endorsed by many experts who take the strengthening of SDR and expansion of the use of SDR as an alternative to the reform of the international monetary system. However, SDR's inherent flaws in its creation make it impossible to replace the hegemony of the dollar. It is neccessary to strengthen the role of SDR in the international monetary system gradually and the inclusion of the RMB in SDR is the entry point for the reform[6].

In the current international reserve assets, the proportion of SDR is less than $4 \%$ and its currency basket only includes USD, EUR, GBP and JPY with the proportion of $41.9 \%, 37.4 \%, 11.3 \%$ and $9.4 \%$ respectively. These currencies all belong to developed economies and they can not reflect the economic contribution and influence of some developing countries today. Since China adopts reform and opening up, the economy has been growing at a high speed. In the New Normal, China focuses on promoting economic transformation and the development prospect is good. At present, China has already become the largest exporter, the second largest economy, the largest commodity trading country and the country with the largest foreign exchange reservesin the world. Meawhile, as China's capital and currency market continues to expand, and the marketization of interest rate and exchange rate advannces steadily, the liberalization of RMB becomes possible. On one hand, the inclusion of the RMB in the SDR contributes 
to changing the irrational distribution of SDRs and increasing its circulation. On the other hand, it helps to expand the use of SDRs as an accepted means of payment in international trade and financial transactions. In addition, it can promote the SDR pricing in international tread and business bookkeeping, and creat SDR assets[7]. This will not only enhance the SDR's international influence, but also meet the national demand for reserve currency. The inclusion of RMB in SDR makes the pricing of commodities more stable.

The inclusion of the RMB in the SDR is conducive to the reform of the IMF. China has made a commitment that China will make a capital increase of 43 billion US dollars to the IMF and promote the IMF reform of general drawing rights, quotas and governance structure and supervision. Therefore, IMF will better play its role in international financial stability and international exchange rate stability.

The inclusion of RMB in SDR will diversify the international reserve currency. $\mathrm{RMB}$ becomes a member of the international currency basket and the world will begin to automatically reserve RMBs. RMB will be likely to become the pricing currency for more international commodity. With China becoming more influential on international affairs, $\mathrm{RMB}$ will get more recognition in international community. Besides, it will steadily promote the diversification of the international reserve currency.

\section{Conclusion}

RMB has been successfully joined the SDR, but it does not have the same position with the US dollar and the Euro. It needs to achieve internationalization by virtue of the policy of " One Belt and One Road" and currecy connection with countries and regions in Asian Investment Bank. The ultimate goal is to make RMB equipped with functions of clearing, investment and reserve as USD and EUR, so that the international monetary system will become more fair and orderly.

\section{References}

[1] Xue Cheng, Li Xinrui. The Entry Point of the International Monetary System Reform - Inclusion of RMB in SDR. Modern Business, (20), pp.107-108, 2016.

[2] Zhang Dingli. The Function and Influence of the Inclusion of RMB in SDR on the Internationalization of RMB. Contemporary Economic Research, (05), pp.59-64, 2016.

[3] Tian Shengbing, Chen Da and Zhao Linlin. A Strategic Analysis of the Inclusion of RMB in SDR. Future and Development, (04), pp.32-35, 2016.

[4] Zhang Monan. The Inclusion of RMB in the SDR Promotes the Major Reform of the International Monetary System. Finance and Economics, (12), pp.11-12, 2015. 
[5] Liu Hong. The Inclusion of RMB in the SDR Promotes the Reform of the International Monetary System. Finance Expo, (11), pp.34-35, 2015.

[6] Song Ke, Li Haoze.A Review of the Reform of RMB,SDR and International Monetary System. International Finance, (07), pp.33-37, 2015.

[7] Liu Ying. A Research on the Inclusion of RMB in SDR. Journal of Regional Finance, (01), pp.34-40, 2014. 